\title{
Standards Promote Credibility and Technology Transfer
}

The Need for Greater Industry Support of Technical Committees

C. Denver Lovett

U.S. DEPARTMENT OF COMMERCE Technology Administration

National Institute of Standards and Technology

Gaithersburg, MD 20899-0001

QC 


\section{Standards Promote Credibility and Technology Transfer}

\section{The Need for Greater Industry Support of Technical Committees}

\section{Denver Lovett}

U.S. DEPARTMENT OF COMMERCE Technology Administration National Institute of Standards and Technology

Gaithersburg, MD 20899-0001

October 1996

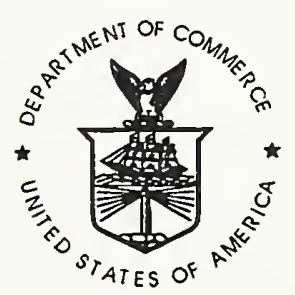

U.S. DEPARTMENT OF COMMERCE Michael Kantor, Secretary

TECHNOLOGY ADMINISTRATION Mary L. Good, Under Secretary for Technology

NATIONAL INSTITUTE OF STANDARDS AND TECHNOLOGY

Arati Prabhakar, Director 



\section{Acknowledgment}

I appreciate the contributions of Tony Bratkovich of the Association for Manufacturing Technology (AMT) who provided input material and held discussion with me during the writing of this article. I also appreciate the contributions of Walter Leight of the NIST Office of Standards Services. Mr. Leight made some valuable suggestions which were considered during the writing of this document. Many thanks to both. 



\section{TABLE OF CONTENTS}

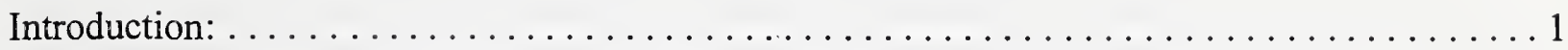

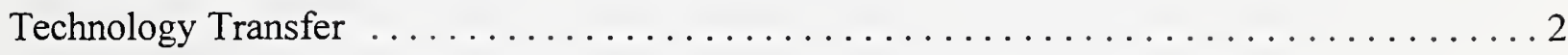

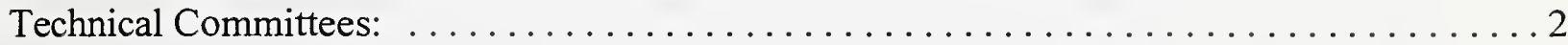

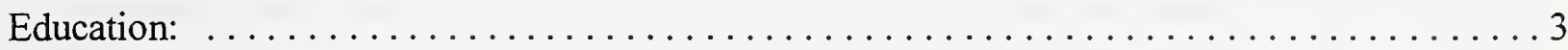

U. S. Industry and Government Should Play a Greater Role in International Standards: . . . . . 4

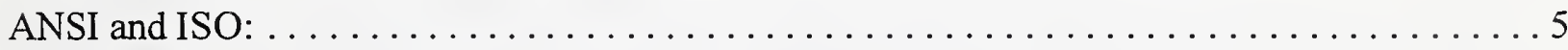

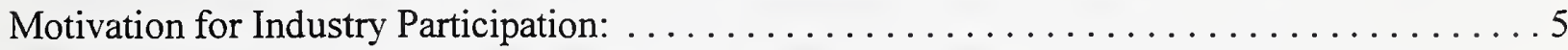

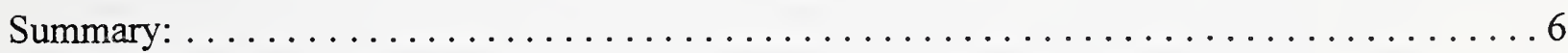

References: ................................... 


\section{Introduction:}

In a dynamic global marketplace, maintaining a competitive edge has become increasingly difficult, because foreign competitors are closing the technological gaps, getting smarter and using standards as effective marketing devices[1]. To meet this challenge U.S. companies must chart a path of continual improvements to reduce operating costs and purchasing costs, and to assure product quality and safety. Many companies may not be aware that domestic and international standardization can help them meet this challenge. Conformance to widely accepted standards recognized by the International Organization for Standardization (ISO), International Electro-technical Commission (IEC) and the American National Standards Institute (ANSI) is helping some companies to get better control of production. This leads to improved quality, reduction in manufacturing lead time, and reduction in time to the marketplace.

Although the U.S. standardization process is a good one, some improvements need to be made to prepare the United States for significant opportunities for leadership in international standards making organizations such as the ISO, IEC, and others. The efficacy of the U.S. standardization process affects U.S. trade and the nation's economy; therefore, it is important that we improve our standards-making process. Some needed improvements include the following: better education programs to increase industry's awareness of the benefits of standards, greater participation by industry in the standard-making process, better understanding of the role of standards in promoting technology transfer, and greater involvement by academia, professional societies, and government in research on a standardization process to meet the needs of the fast pace of technology in the global economy.

There are many ways of setting standards. The intent of this paper is not to call attention to all mutually exclusive types of standards, but rather to indicate how standards may be used to specify the nature of products. In addition, this paper will briefly describe the nature of the standards-making process, and/or government requirements for regulatory responsibilities. The development of federal regulations according to the Office of Management Budget's Circular A-119 [2] and the recently enacted Technology Transfer and Advancement Act [3 ], requires consideration of private sector consensus standards as a basis for initiation.

Three most common standards are: product standards, regulatory control standards, and process standards. Standards may be achieved in three different ways: standards can be set by the marketplace--- a de facto standard; standards can be mandated by the government --- regulatory; and standards can be negotiated through a voluntary private sector consensus process[1]. This article focuses on product performance standards by the voluntary consensus-based process.

The intent of this paper is to call attention to the need for greater industry participation in both national and international standards committees. This need is described by giving an overview of U.S. standardization by the voluntary consensus-based process and describing some of the 
benefits of participating in standards-developing committees. The U.S. National Machining Center Standards Committee is cited as an example of a voluntary consensus-based process, involving cooperation among industry, government and academia.

\section{Technology Transfer:}

Standards play a key role in the process of technology diffusion. When advanced technologies from industry, government laboratories, and academia are included in a standard and used by others, those technology advances are then diffused throughout industry. This process raises productivity and competitiveness by enabling firms to adopt standardized approaches, when appropriate, rather than reinventing technology already available [4]. For example, a machining center standard titled "Methods for Performance Evaluation of Numerically Controlled Machining Centers" was adopted as ANSI standard in 1992 . A by-product of the machining center standard is a gradual infusion of technology for evaluating the performance of machine tools. These new technologies/methodologies include the telescoping ball bar, new applications for capacitance gages, a method of evaluating multi-axis machining performance, a method for assessing a machine's susceptibility to chatter, and methods for evaluating a machine's capability to measure parts [5]. The secretariat for this standard is the American Society of Mechanical Engineers (ASME), and this standard is designated as ASME B5.54-1992. This B5.54 Standard [6] is the impetus which motivated both large and small companies to increase their awareness of the technology mentioned above, and to use it in evaluating the performance of their machining centers. The adoption of the best industrial practices and technologies throughout industry is a crucial factor in supporting the nation's industrial competitiveness and economic performance [4].

There are 380,0000 small and medium size firms [7] in the United States, many of which are involved in some type of machining operation. These firms could use the guidance provided by national and international standards. Standards can help them improve quality, reduce labor, and increase productivity [5]. Standards are also often required by prime contractors. For example, Boeing-Seattle requested ${ }^{1}$ some of its suppliers to perform the ONE-DAY test of the B5.54 Standard as part of a supplier certification program.

\section{Technical Committees:}

The process for developing standards should be fair and, through committee balance, prevents any single interest group from dictating the outcome. One way of achieving this is to use the voluntary consensus-based process, which emphasizes openness, due process and transparency. The committee members generally come from all directly and materially affected interests, for example producers, suppliers, users, government and academic communities. When standards

${ }^{1}$ Karl Beracz of Beacon Metrology, Inc., reported this at the ASME/B5 TC52 Committee meeting. 
are developed with a balanced perspective of the users, producers, and suppliers, the standards will convey consistent and understandable information about the product to the buyer [4]. This will promote technology transfer between the supplier community and user community. The standards development process starts with the technical committees that do the work of developing drafts of standards and also deciding on reaffirmation and revisions to published standards. A learning process usually occurs within these groups. The voluntary consensus process requires cooperation and trust to succeed. There must be a sharing of the knowledge domain of each group, a respect for the strengths and the limitations imposed on each group's domain. This learning process is necessary in order to develop the basis for moving toward a common agenda of publishing a standard that will promote the manufacture of superior products, which will flow to the end-user.

Consider machine tools as an example. In this case, the users are interested in purchasing a machine tool which makes products to meet design specifications. The supplier of the machine tool is interested in building machine tools to satisfy the performance expectations of the potential users. The users must determine which machining performance parameters to specify that are pertinent to the machining of quality products, while the builder must have reasonable expectations of the performance parameters which users are likely to demand. Without common terminology and expectations of performance parameters that are traceable to a national or international standard, these expectations and terminology become blurred, and may become the seeds for misunderstanding, misrepresentation, disputes and possibly law suits. Such situations add to the ultimate cost of doing business. National standards and international standards minimize the likelihood that these situations will occur by providing unifying terminology and methods for evaluating performance, as agreed upon by both user and supplier communities and all other interested parties.

\section{Education:}

A properly written standard not only facilitates buying and selling, but also educates users and suppliers in the latest technology. Education is a precursor to technology transfer. To achieve greater use of standards, there must also be an education program that increases the awareness of the benefits of standards. If increased awareness of the benefits of standards is achieved, this leads to increased support for standards, and increased participation in technical committees for both national and international standards activities. One level of education can be conducted by technical committees. Technical committees can perform activities of promoting and educating the public about the utility of the standards which they have developed. For example, some members of the B5 technical committee 52 participate in seminars on the B5.54 Standard. These seminars are held at industry trade shows, and are usually sponsored by the Society of Manufacturing Engineers. Video tapes pertaining to the B5.54 Standard were made to promote the awareness of the standard. Broader awareness could be accomplished through the Internet and World Wide Web. A home page for each technical committee could be used to describe the scope of the committee and the benefits of the standard and its relationship to international technical committees. This type of activity would give the public broad access to information 
about national and international standards committees. Information and communication technology can play a critical role in educating the public about standards as well as speeding up the productivity of the standards making process.

A resource that has been barely tapped is the academic community. It can play an important role in increasing the national competence in dealing with standards. Few schools of engineering and business provide course material or sponsor research that focuses on standards. There are a few exceptions ${ }^{2}$. Most of the current research focuses on existing problems. However, little work is being done to anticipate future standardization problems and the economic impact of standards. Given the challenges presented by fast-moving technology and the highly competitive global economy, the federal government and academia should perform research on future standards needs and future standardization processes and procedures [1].

\section{U. S. Industry and Government Should Play a Greater Role in International Standards:}

Some major industrial countries are better organized to influence the international standards setting process, often to the detriment of U.S. trade. The United States has sometimes underestimated other governments' efforts to use standards as marketing devices. There is a significant advantage to being first to publish a standard and in getting it widely accepted, both nationally and internationally. Most of our foreign competitors are well aware of such advantages/benefits and consider it an honor and a privilege when called upon to assist in their national standards efforts by joining committees or providing input to their national committees.

The failure to recognize the implications of national and international standards can have serious consequences for U.S. industry. For example, during the 1980's there was no U.S. standard nor ISO standard for machining centers. A widely accepted national standard could have saved hundreds of "staff-years" in the process of writing specifications which are required for purchasing and accepting machine tools ${ }^{3}$. Furthermore, the absence of such standards made it easier for some competitors to make unsubstantiated claims; thus reducing the ability of U.S. machine tool builders to compete in their own country. A slightly different problem occurred when U.S. machine tool builders tried to export their machines abroad. In the absence of an international standard, it was necessary to conform to a variety of unfamiliar foreign standards, with the accompanying administrative and technical costs associated with conformance to several national standards.

The situation has improved since the eighties. In 1992, ANSI adopted and ASME approved an American National Standard for machining centers. A standard for turning centers is being

2 The two exceptions of which the author is aware are the University of North Carolina-Charlotte and the University of Florida-Gainesville.

${ }^{3}$ Dr. Robert Hocken, Letter \& Notes; University of North Carolina-Charlotte, 1989. 
developed by the same ASME technical committee ${ }^{4}$ that developed the machining center standard. Also, U.S. participation in corresponding international standards committees has significantly improved. These standards writing activities consisted of the collective efforts of a professional society, an industry trade association, government laboratories, academia, machine tool builders and machine tool users. The government laboratories include the National Institute of Standards and Technology (NIST), Lawrence Livermore National Laboratory, and Los Alamos National Laboratory; the Association for Manufacturing Technology is the industry association; and the universities are University of North Carolina-Charlotte and University of Florida-Gainesville. Several major machine tool builders and machine tool users were also involved in the development of the machine tool standard. This is an example in which diverse groups developed a consensus-based standard that has a balanced perspective from the viewpoint of both the machine tool builders and machine tool user. Over the long term, this standard will facilitate the flow of machine tools between buyers and sellers, both in the domestic and international markets. There are some positive U.S. machine tool market trends that have begun to develop; however, it is too early to link these trends with the standardization efforts.

\section{ANSI and ISO:}

Since rules are essential for fair competition, it is prudent to have a representative at the table where the rules are being made. One of the best ways to participate in the rule-making process is through active participation in technical committees that are developing national standards and interfacing with international standards organizations[8].

The coordination of standards development activities in the United States and representation to other international standards organizations are provided under the auspices of the ANSI, whose membership consists of 1300 companies, 250 organizations and 30 government agencies. Each company, organization, and government agency financially supports ANSI according to a formula. ANSI, in turn, is the U.S. membership body and sponsors the U.S. National committees in both the ISO and the IEC. ANSI is the primary national coordinating body for U.S. standards development organizations.

Since ANSI members pays their dues and ANSI pays for ISO membership, it seems prudent that companies should follow through to get full expert representation by participating in the U.S. Technical Advisory Groups (TAG). These technical committees are the sounding boards for new national proposals that a U.S. TAG presents to the ISO. They also make comments on other countries' proposals. ANSI coordinates the formation of U.S. TAGs corresponding to the technical committees at the national level.

\section{Motivation for Industry Participation:}

4 The designation is ASME B5/TC52. 
Some of the reasons industry should participate in standards are to: (1) promote commercialization of products, (2) stimulate technology diffusion, (3) enhance competition, (4) provide for product compatibility between mating parts, (5) organize manufacturing processes in accordance with a standard and (6) direct public welfare in accordance with some established national goals.

Some manufacturers have a need to grade and classify their products, especially when the product types are intended for separate distribution channels. In addition, manufacturers need to have some means of differentiating their products from their competitors. Product performance standards provide opportunities and means for doing these things.

Manufacturers are usually bewildered by the fast pace of technology. This bewilderment is sometimes caused by a rapidly changing environment in which there is a lack of agreed-upon common terminology and a lack of uniformly accepted performance measures. This growing pace of technology will become the impetus for more standardization because standards setting can reduce the uncertainty in a rapidly changing environment. Most businesses are interested in reducing uncertainty in order to improve their planning and their production of acceptable parts. Participants in the process learn first-hand about new technologies; they contribute to forming the common terminology; and they help to develop the scientific basis and rules for evaluating product performance.

Users of products are demanding greater performance. For machine tools, this includes greater accuracy, increased feed rates, higher spindle speeds, and increased stiffness. Standards help users by conveying product information and providing a basis for quality control. This is especially true when the standards are performance-based rather than design-based. When standards are implemented to focus on manufacturing processes, both manufacturing productivity and the quality of the end-product can be significantly improved [5].

Participation in standards-writing activities of technical committees provides company benefits as well as individual satisfaction. For the company, the benefits include: (1) the ability to comply with the latest standards without delay; (2) first-hand access to knowledge of the technical and legal environment affecting its products; (3) the measures to compare its product with its competitor's; and (4) readiness in anticipation of future standard releases. For the individual (employee), participation will gain: (1) an opportunity to learn about customers and the industry through appropriate discussion with peers at committee meetings; (2) educational benefits resulting from meetings and negotiations with other experts in the field; and (3) recognition among customers and competitors as a leader in the field [8].

\section{Summary:}

Participation by diverse groups in the development of standards helps to build confidence in the standardization process. This confidence can lead to more credible product information, especially when the product information is determined by a national standard or international standard. Standards often level the playing field when all manufacturers apply the same rules in 
evaluating the performance of their products. Under these conditions, standards could become a competitive advantage when a company participates in standard activities and share in the benefits (1), (2), (3) and (4) above. When these conditions exist, the suppliers and buyers sense fairness, and they share trust. These conditions promote technology transfer between the suppliers and buyers. The national impact of a standard often depends on how widely it is accepted and used. Improved methods of educating potential users about the benefits of standards are needed. Finally, participation in the standardization process can improve exports of our country, improve the competitive position of firms and provide industry recognition and personal satisfaction for employees.

\section{References:}

[1] U.S. Office of Technology Assessment, Global Standards: Building Blocks to the Future, Government Printing Office, Washington, D.C., March 1992.

[2] Office of Management and Budget, Circular No. A-119, revised October 20, 1993

[3] United States Congress, Public Law 104-113, Section 12, 104th Congress, March 7, 1996

[4] National Research Council, Standards, Conformity Assessment, and Trade, National Academy Press, Washington, D.C., 1995.

[5] Lovett, C. D., "Machine Performance Standards Provides Opportunity to Improve Quality and Productivity," Mechanical Engineer, ASME, November 1995, p. 120

[6] ANSI/ASME, Methods for Performance Evaluation of Numerically Controlled Machining Centers (ASME B5.54-1992); The American Society of Mechanical Engineer, 1993.

[7] Bureau of Census, County Business Patterns, U.S. Department of Commerce, 1992.

[8] Standards Handbook, Association for Manufacturing Technology, First Edition, March 1994. 

